() Open Access Full Text Article

\title{
A molecular mechanism for diacylglycerol-mediated promotion of negative caloric balance
}

This article was published in the following Dove Press journal:

Diabetes, Metabolic Syndrome and Obesity:Targets and Therapy

16 December 2009

Number of times this article has been viewed

\section{Hidekatsu Yanai ${ }^{1,2}$ \\ Yoshiharu Tomono 3 \\ Kumie Ito ${ }^{1,2}$ \\ Yuji Hirowatari ${ }^{4}$ \\ Hiroshi Yoshida ${ }^{1,5}$ \\ Norio Tada ${ }^{1,2}$}

'Department of Internal Medicine, ${ }^{2}$ Institute of Clinical Medicine and Research, ${ }^{3}$ Department of Nutrition, ${ }^{5}$ Department of Laboratory Medicine, Jikei University School of Medicine, Chiba, Japan; ${ }^{4}$ Bioscience Division,

Tosoh Corporation, Kanagawa, Japan
Correspondence: Hidekatsu Yanai Division of General Medicine, Department of Internal Medicine, Kashiwa Hospital, The Jikei University School of Medicine, 163-I, Kashiwashita, Kashiwa, Chiba 277-8567, Japan

Tel +8I 47164 IIII

Email yanaih@jikei.ac.jp
Aims: A substitution of diacylglycerol (DAG) oil for triacylglycerol (TAG) oil in diet has been reported to reduce body fat and body weight, possibly by increasing postprandial energy expenditure (EE). We have previously studied plasma serotonin, which increases EE and exists in the small intestine, in individuals who ingested TAG and DAG oil, and found that DAG ingestion elevates plasma serotonin levels by about $50 \%$ compared with TAG ingestion. We studied the molecular mechanisms for DAG-mediated increase in serotonin and EE.

Methods: We studied effects of 1-monoacylglycerol and 2-monoacylglycerol, distinct digestive products of DAG and TAG, respectively, on serotonin release from the Caco-2 cells (the human intestinal cell line, $n=8$ ). Further, we studied effects of 1- and 2-monoacylglycerol, and serotonin on expression of mRNA associated with $\beta$-oxidation, FA metabolism, and thermogenesis, in the Caco-2 cells $(n=5)$.

Results: 1-monoacylglycerol (100 $\mu \mathrm{M}$ 1-monooleyl glycerol [1-MOG]) significantly increased serotonin release from the Caco-2 cells compared with 2-monoacylglycerol (100 $\mu \mathrm{M} 2$-MOG) by $36.6 \%$. Expression of mRNA of acyl-CoA oxidase (ACO), fatty acid translocase (FAT), and uncoupling protein-2 (UCP-2) were significantly higher in $100 \mu \mathrm{M} 1$-MOG-treated Caco-2 cells than $100 \mu \mathrm{M}$ 2-MOG-treated cells by $12.8 \%, 23.7 \%$, and $35.1 \%$, respectively. Further, expression of mRNA of ACO, medium-chain acyl-CoA dehydrogenase, FAT, and UCP-2 were significantly elevated in serotonin $(400 \mathrm{nM})$-treated Caco-2 cells compared with cells incubated without serotonin by $28.7 \%, 30.1 \%$, and $39.2 \%$, respectively.

Conclusions: Our study demonstrated that 1-monoacylglycerol, a digestive product of DAG, increases serotonin release from the Caco- 2 cells, and enhances expression of genes associated with $\beta$-oxidation, FA metabolism, and thermogenesis, and that serotonin increases expression of these genes, proposing a novel molecular mechanism for DAG-mediated promotion of negative caloric balance.

Keywords: diacylglycerol, energy expenditure, intestine, serotonin, triacylglycerol

\section{Introduction}

Diacylglycerol (DAG) is a natural component of various edible oils. DAG has been reported to be more effective for preventing excess adiposity through a variety of potential mechanisms in comparison with triacylglycerol (TAG) in humans. ${ }^{1}$ In a study that examined the effects of DAG-rich diet on postprandial energy expenditure (EE) and respiratory quotient (RQ), the amount of changed EE after DAG ingestion was higher than that after TAG ingestion, and RQ after DAG ingestion was significantly lower than that after TAG ingestion, suggesting that DAG increases EE by inducing higher lipid oxidation compared with $\mathrm{TAG}^{2}$ We have previously studied plasma serotonin, 


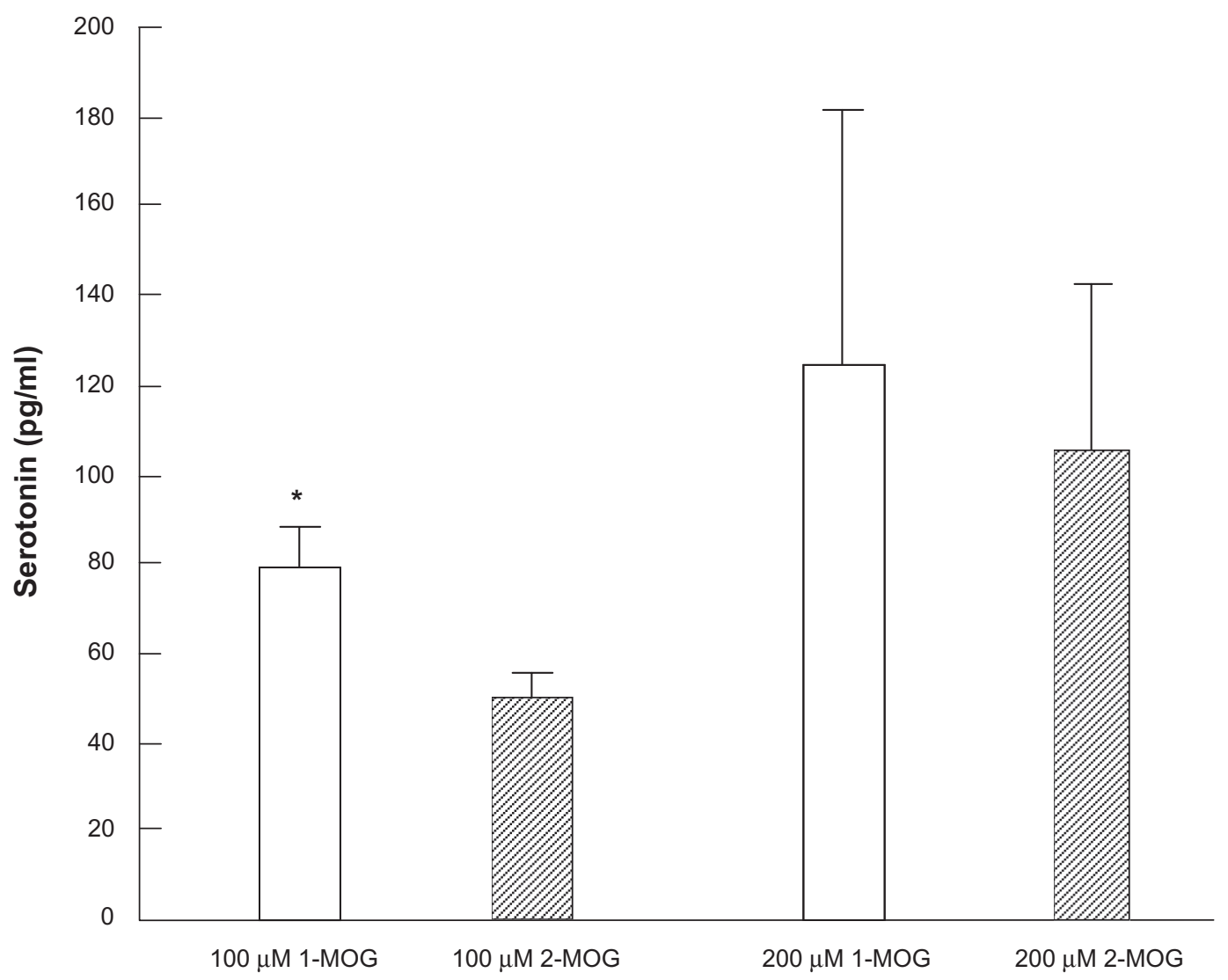

Figure I Effects of I-monooleyl glycerol (I-MOG) and 2-monooleyl glycerol (2-MOG) on serotonin release from the Caco-2 cells. Notes: Boxes and bars indicate mean $\pm S D . N=8 . * P<0.001$ versus 2-MOG-treated cells.

which increases EE and body temperature, in subjects who ingested TAG and DAG. ${ }^{3}$ In that study, we found that DAG oil ingestion elevates plasma serotonin levels by about $50 \%$, compared with TAG oil ingestion, suggesting a possible mechanism for postprandial increase in EE by DAG.

Dietary TAG oil is hydrolyzed by lipase to free fatty acids (FFA) and 2-monoacylglycerol in the intestinal lumen, and these metabolites are absorbed by intestinal cells. ${ }^{1}$ In the case of DAG oil, the metabolic pathway in the intestinal cells is different from that of TAG oil. 1,3-DAG, the main form of DAG oil, would be hydrolyzed to 1-monoacylglycerol and FFA. ${ }^{1}$ To understand how DAG ingestion increases plasma serotonin levels as compared with TAG ingestion, we studied effects of 1-monoacylglycerol and 2-monoacylglycerol, hydrolytic products of DAG and TAG, respectively, on serotonin release from the intestinal cells, the Caco-2 cells. Further, we studied effects of serotonin, 1- and 2-monoacylglycerol on expression of mRNA of acyl-CoA oxidase (ACO), medium-chain acyl-CoA dehydrogenase (MCAD), fatty acid translocase (FAT), and uncoupling protein-2 (UCP-2), which are associated with $\beta$-oxidation, FA metabolism, and thermogenesis.

\section{Materials and methods}

\section{Cells}

Caco-2 cells were obtained from ATCC (American Type Culture Collection, Manassas, VA). Caco-2 cells were grown in $75-\mathrm{cm}^{2}$ plastic flasks at $37{ }^{\circ} \mathrm{C}$ in a $5 \% \mathrm{CO}_{2} 95 \%$ air environment. The culture medium consisted of Dulbecco's modified Eagle's medium (DMEM), 20\% fetal bovine serum (FBS), $100 \mathrm{IU} / \mathrm{ml}$ penicillin, and $100 \mu \mathrm{g} / \mathrm{ml}$ streptomycin. Cells reached confluence after 4-5 days in culture.

\section{Effects of I-monooleyl glycerol (I-MOG) and 2-MOG on serotonin release and expression of mRNA of ACO, MCAD, FAT, and UCP-2 in the Caco-2 cells}

1-MOG and 2-MOG were purchased from Doosan Serdary Research Laboratories (Toronto, ON, Canada), and were dissolved and dispersed in $10 \mathrm{mmol} / 1$ taurocholate in phosphate-buffered saline (PBS), $\mathrm{pH} 7.4$, to obtain the desired concentration, and were further incubated for one hour at $37{ }^{\circ} \mathrm{C}$ with shaking at $90 \mathrm{rpm}$ to obtain a homogeneous solution. The stable monomer concentrations 
A

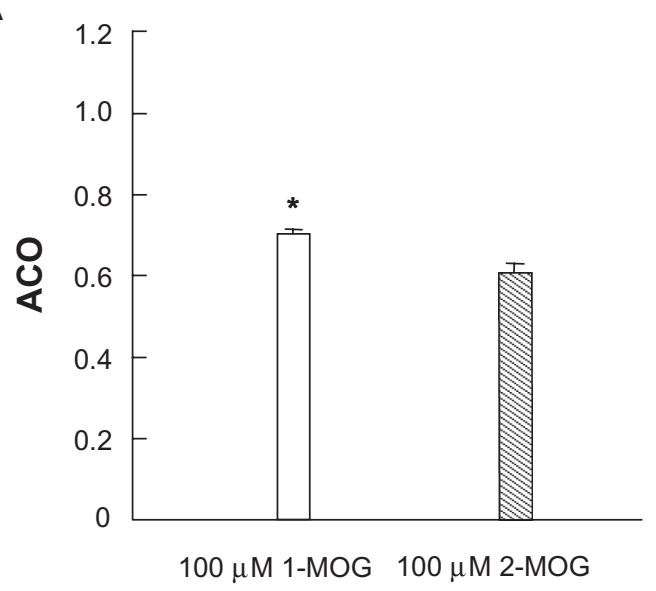

B

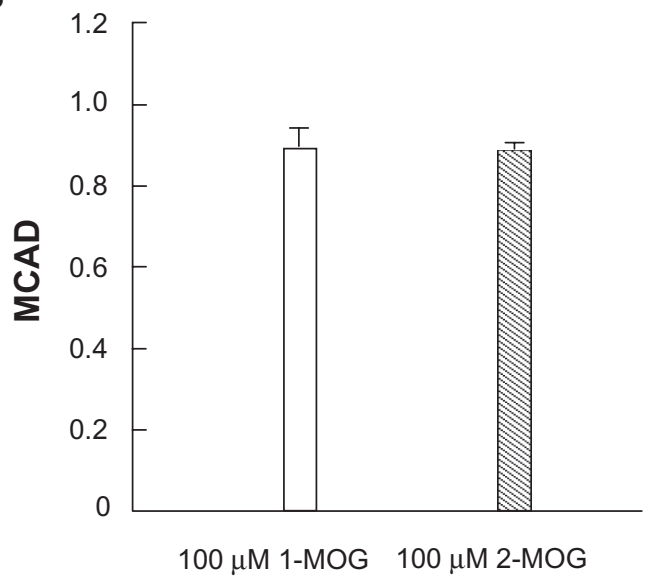

C

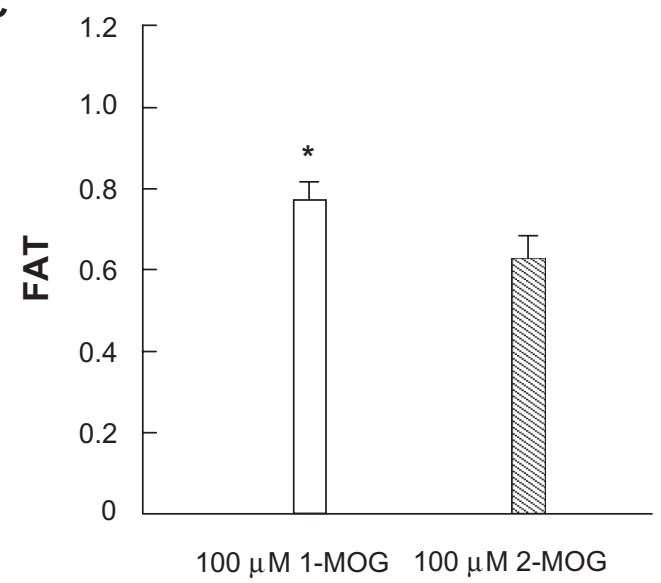

D

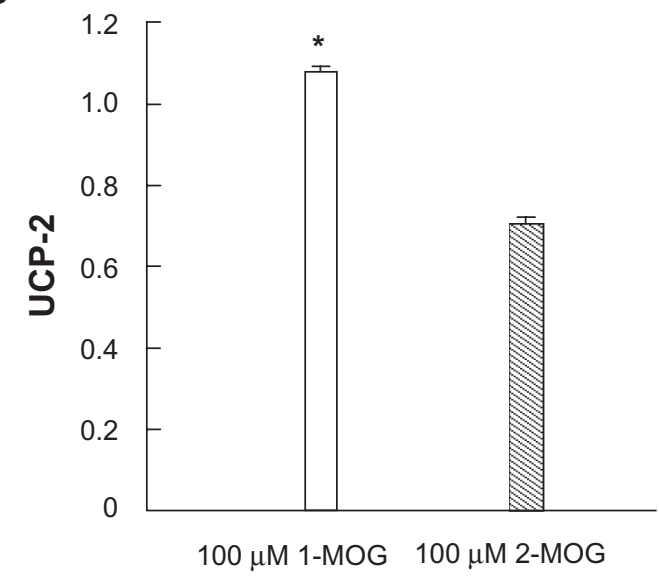

Figure 2 Effects of $100 \mu \mathrm{MI}$ I-monooleyl glycerol (I-MOG) and 2-monooley glycerol (2-MOG) on expression of mRNA of acyl-CoA oxidase (ACO) A) medium-chain acyl-CoA dehydrogenase (MCAD) B) fatty acid translocase (FAT) C) and uncoupling protein-2 (UCP-2) D) in the Caco-2 cells.

Notes: Boxes and bars indicate mean \pm SD of relative quantitation mRNA values using I8S as an internal control. $\mathrm{N}=8$. $* P<0.00 \mathrm{I}$ versus 2 -MOG-treated cells.

for oleic acid and 2-monoacylglycerol have been reported to be $<200 \mu \mathrm{M}$ and $<125 \mu \mathrm{M}$, respectively. ${ }^{4}$ The Caco-2 cells were then incubated with medium containing $100 \mu \mathrm{M}$ and $200 \mu \mathrm{M} 1-\mathrm{MOG}$ or $2-\mathrm{MOG}$ at $37^{\circ} \mathrm{C}$ for 24 hours, and serotonin concentrations in the medium were measured by a previously reported method. ${ }^{5}$ Briefly, serotonin was separated by high-performance liquid chromatography with column-switching system, and was specifically converted into a fluorescent derivative with benzylamine for convenient detection. ${ }^{5}$

Total RNA was extracted from the Caco- 2 cells, and cDNA was synthesized using $1 \mu \mathrm{g}$ of total RNA by reverse transcription after treatment with DNase. Quantitative polymerase chain reaction (PCR) was done using the 7500 Real-Time PCR system and the TaqMan Gene Expression Assay system (Applied Biosystems, Foster City, CA). Gene expression analyses of ACO, MCAD, FAT, and UCP-2 were performed by relative quantitation (RQ) assay using $18 \mathrm{~S}$ as an internal control. The Taqman Gene Expression Assays
Hs01074241, Hs00936576, Hs01567186, Hs01075227, and Hs99999901_S1 were used for ACO, MCAD, FAT, UCP-2, and $18 \mathrm{~S}$, respectively.

\section{Effects of serotonin on expression of mRNA of ACO, MCAD, FAT, and UCP-2}

Caco- 2 cells were incubated with medium without and with $50 \mathrm{nM}$ and $400 \mathrm{nM}$ serotonin at $37{ }^{\circ} \mathrm{C}$ for 24 hours. Total RNA was extracted from the Caco-2 cells, and cDNA was synthesized using $1 \mu \mathrm{g}$ of total RNA by reverse transcription after treatment with DNase. Quantitative PCR was done using the 7500 Real-Time PCR system and the TaqMan Gene Expression Assay system (Applied Biosystems). Gene expression analyses of ACO, MCAD, FAT, and UCP-2 were performed by Relative RQ assay using $18 \mathrm{~S}$ as an internal control. The Taqman Gene Expression Assays Hs01074241, Hs00936576, Hs01567186, Hs01075227, and 
A

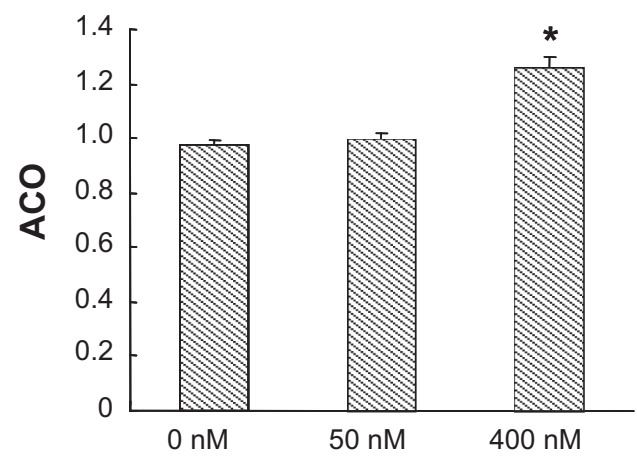

B

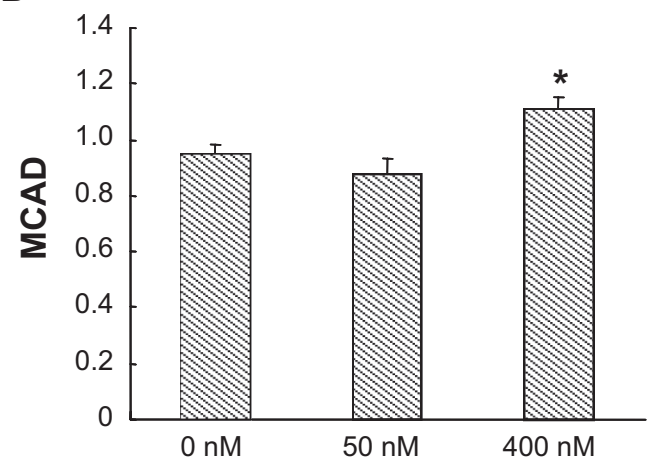

C

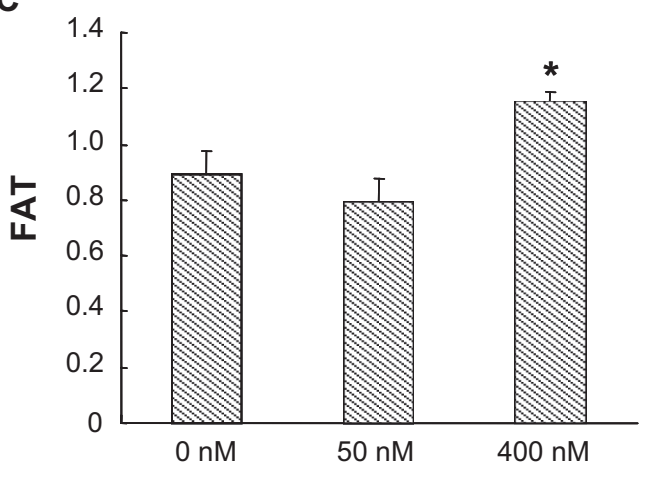

D

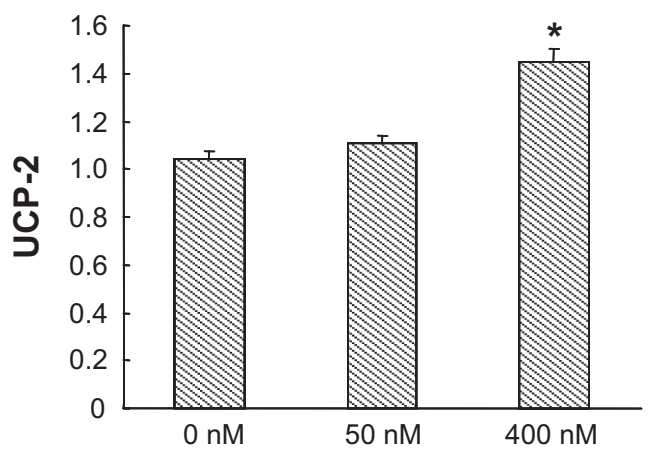

Figure 3 Effects of serotonin on expression of mRNA of acyl-CoA oxidase (ACO) A) medium-chain acyl-CoA dehydrogenase (MCAD) B) fatty acid translocase (FAT) C) and uncoupling protein-2 (UCP-2) D) in the Caco-2 cells.

Notes: Boxes and bars indicate mean \pm SD of relative quantitation mRNA values using $18 \mathrm{~S}$ as an internal control. $\mathrm{N}=5$. $* P<0.0005$ versus 0 and $50 \mathrm{nM}$ serotonin-treated cells.

Hs99999901_S1 were used for ACO, MCAD, FAT, UCP-2, and $18 \mathrm{~S}$, respectively.

\section{Statistical analysis}

Values were expressed as mean \pm standard deviation (SD). Comparison of serotonin concentration in the medium of Caco-2 cells treated with 1-MOG and 2-MOG was analyzed using the Mann-Whitney $U$ test. Comparison of mRNA expressions of ACO, MCAD, FAT, and UCP-2 in the Caco-2 cells incubated with 1-MOG and 2-MOG was analyzed using the Mann-Whitney $U$ test. Comparisons in mRNA expressions of ACO, MCAD, FAT, and UCP-2 in the Caco-2 cells incubated with different concentrations of serotonin, were analyzed by one-factor analysis of variance (ANOVA) and Scheffe's $F$ test.

\section{Results}

$100 \mu \mathrm{M}$ 1-MOG significantly increased serotonin release from the Caco-2 cells compared with $100 \mu \mathrm{M} 2-\mathrm{MOG}$ by $36.6 \%(P<0.001$, Mann-Whitney $U$ test) (Figure 1$)$. Although a statistical significant difference was not obtained, increased serotonin release was observed in the Caco- 2 cells treated with $200 \mu \mathrm{M} 1-\mathrm{MOG}$ as compared with cells treated with $200 \mu \mathrm{M}$ 2-MOG.

Expression of mRNA of ACO, FAT, and UCP-2 were significantly higher in $100 \mu \mathrm{M}$ 1-MOG-treated Caco-2 cells than $100 \mu \mathrm{M} 2-\mathrm{MOG}-$ treated cells by $12.8 \%(P<0.01)$, 23.7\% $(P<0.01)$, and $35.1 \%(P<0.01)$, respectively (Figure 2).

Further, expression of mRNA of ACO, MCAD, FAT, and UCP-2 were significantly elevated in serotonin (400 nM)treated Caco-2 cells compared with cells incubated without serotonin by $28.7 \%(P<0.01), 30.1 \%(P<0.01)$, and $39.2 \%$ $(P<0.01)$, respectively.

\section{Discussion}

Upregulated mRNA expression associated with mitochondrial and peroxisomal $\beta$-oxidation and thermogenesis in the small intestine may explain in part mechanism for DAG-mediated increase in postprandial EE. ${ }^{6,7}$ The small intestine is likely to be the key organ to make differences in energy metabolism between DAG and TAG. Serotonin is present in great quantity in the small intestine, and is associated with increase in oxygen consumption and body 
temperature. ${ }^{8,9}$ An administration of a serotonin receptor agonist significantly increased body temperature and $\mathrm{EE}$ in Zucker rats in a dose-dependent manner, and a selective serotonin receptor antagonist completely inhibited this increase in EE, suggesting that serotonin regulates thermogenesis and EE. ${ }^{10}$ A single injection of serotonin in rats stimulated resting oxygen consumption; this was reduced by pretreatment with automatic nerve ganglion blocking agent, indicating that serotonin mediates peripheral sympathetic thermogenesis. ${ }^{11}$ We have previously studied plasma serotonin in subjects who ingested TAG and DAG, and found that DAG oil ingestion elevates plasma serotonin levels by about $50 \%$ compared with TAG oil ingestion, suggesting a possible mechanism for postprandial increase in EE by DAG. ${ }^{3}$

To reveal further molecular mechanisms underlying this effect of DAG, we performed this study. We demonstrated that 1-MOG, a digestive product of DAG, significantly increased serotonin release, and also enhanced expression of mRNA of ACO, FAT, and UCP-2, compared with 2-MOG, a digestive product of TAG, in the Caco- 2 cells. Further, our study showed that serotonin upregulates expression of mRNA associated with $\beta$-oxidation, FA metabolism, and thermogenesis. These results suggest that a digestive product of DAG increases serotonin release, and serotonin induces expression of genes associated with elevation in energy expenditure, and consequently leading to DAG-mediated promotion of negative caloric balance. To our knowledge, the present study is the first to report serotonin-mediated elevation in expression of genes associated with $\beta$-oxidation, FA metabolism, and thermogenesis. However, it remains unclear how much 1- or 2-monoacylglycerol exists in the intestine when we ingested DAG or TAG oil. Therefore, we exactly don't know whether or not the concentrations used in our studies are similar to those expected in a natural biological system or simply artificial. To make our preliminary results valid and meaningful, we should investigate the concentration of metabolites in the intestine after TAG or DAG oil ingestion, and should also study a dose-dependent and a time-dependent effect of serotonin and 1-, 2-monoacylglycerol for expression of genes associated with $\beta$-oxidation, FA metabolism, and thermogenesis.

More than $90 \%$ of total body content of serotonin is synthesized, stored and released by intestinal enterochromaffin cells. Activation of the various receptors such as cholinergic, nicotinic, and serotonin 3 receptors, trigger intracellular messenger systems, which regulate the secretion of serotonin. ${ }^{12}$ Monoacylglycerol has been reported to act as an endogenous ligand for the cannabinoid receptors, ${ }^{13}$ which seem to be involved in serotonin 3 receptors. ${ }^{14}$ Although we should perform more studies to elucidate the underlying mechanism in the future, 1-monoacylglycerol may be more strongly associated with stimulatory receptors for serotonin release from the enterochromaffin cells compared with 2-monoacylglycerol.

Serotonin has been reported to be associated with vasoconstriction and platelet function. ${ }^{15}$ In our previous study, ${ }^{3}$ we studied plasma von-Willebrand factor, thrombomodulin, and p-selection in individuals who ingested TAG and DAG, and did not observe a significant difference between TAG and DAG ingestion (data not shown). A significance of DAGmediated increase in plasma serotonin for atherosclerosis remains unclear, which should be elucidated.

In conclusion, our study demonstrated that a hydrolytic product of DAG increases serotonin release from the Caco-2 cells, and enhances expression of genes associated with $\beta$-oxidation, thermogenesis, and FA metabolism, which were also upregulated by serotonin, proposing a new molecular biological mechanism for DAG-induced promotion of negative caloric balance.

\section{Disclosures}

The authors report no conflicts of interest in this work.

\section{References}

1. Yanai $\mathrm{H}$, Tomono $\mathrm{Y}$, Ito $\mathrm{K}$, et al. Diacylglycerol oil for the metabolic syndrome. Nutr J. 2007;6:43.

2. Saito S, Tomonobu K, Hase T, et al. Effects of diacylglycerol on postprandial energy expenditure and respiratory quotient in healthy subjects. Nutrition. 2006;22:30-35.

3. Yanai H, Yoshida H, Tomono Y, et al. Effects of diacylglycerol on glucose, lipid metabolism, and plasma serotonin levels in lean Japanese. Obesity (Silver Spring). 2008;16:47-51.

4. Murota K, Storch J. Uptake of micellar long-chain fatty acid and sn-2-monoacylglycerol into human intestinal Caco-2 cells exhibits characteristics of protein-mediated transport. J Nutr. 2005;135: $1626-1630$.

5. Hirowatari Y, Hara K, Kamihata H, et al. High-performance liquid chromatographic method with column-switching and post-column reaction for determination of serotonin levels in platelet-poor plasma. Clin Biochem. 2004;37:191-197.

6. Murase T, Nagasawa A, Suzuki J, et al. Dietary alpha-linolenic acid-rich diacylglycerols reduce body weight gain accompanying the stimulation of intestinal beta-oxidation and related gene expressions in C57BL/KsJ$\mathrm{db} / \mathrm{db}$ mice. J Nutr. 2002;132:3018-3022.

7. Murase T, Aoki M, Wakisaka T, et al. Anti-obesity effect of dietary diacylglycerol in C57BL/6J mice: dietary diacylglycerol stimulates intestinal lipid metabolism. J Lipid Res. 2002;43:1312-1319.

8. Resnick RH, Gray SJ. Distribution of serotonin (5-hydroxytryptamine) in the human gastrointestinal tract. Gastroenterology. 1961;41: $119-121$.

9. Mazzola-Pomietto P, Aulakh CS, Wozniak KM, et al. Evidence that $\mathrm{m}$-chlorophenylpiperazine-induced hyperthermia in rats is mediated by stimulation of 5-HT2C receptors. Psychopharmacology (Berl). 1996;123:333-339. 
10. Hayashi A, Sonoda R, Kimura Y, et al. Antiobesity effect of YM348, a novel 5-HT2C receptor agonist, in Zucker rats. Brain Res. 2004;1011:221-227.

11. Rothwell NJ, Stock MJ. Effect of diet and fenfluramine on thermogenesis in the rat: possible involvement of serotonergic mechanisms. Int J Obesi. 1987;11:319-324.

12. Hansen $\mathrm{MB}$, Witte $\mathrm{AB}$. The role of serotonin in intestinal luminal sensing and secretion. Acta Physiol (Oxf). 2008;193:311-323.
13. Dinh TP, Carpenter D, Leslie FM, et al. Brain monoglyceride lipase participating in endocannabinoid inactivation. Proc Natl Acad Sci USA. 2002;99:10819-10824.

14. Rácz I, Bilkei-Gorzo A, Markert A, et al. Anandamide effects on 5-HT(3) receptors in vivo. Eur J Pharmacol. 2008;596:98-101.

15. Mohammad-Zadeh LF, Moses L, Gwaltney-Brant SM. Serotonin: a review. J Vet Pharmacol Ther. 2008;31:187-199.

\section{Publish your work in this journal}

Diabetes, Metabolic Syndrome and Obesity: Targets and Therapy is an international, peer-reviewed open-access journal committed to the rapid publication of the latest laboratory and clinical findings in the fields of diabetes, metabolic syndrome and obesity research. Original research, review, case reports, hypothesis formation, expert opinion and commentaries are all considered for publication. The manuscript management system is completely online and includes a very quick and fair peer-review system, which is all easy to use. Visit http://www.dovepress.com/testimonials.php to read real quotes from published authors.

Submit your manuscript here: http://www.dovepress.com/diabetes-metabolic-syndrome-and-obesity-targets-and-therapy-journal 